\title{
The Comparative Phonology of Konsoid
}

\author{
Wondwosen Tesfaye ** \\ (Addis Ababa University, Ethiopia)
}

\begin{abstract}
This study compares the phonology of Konso, Diraytata and Mosittacha languages which belong to the Konsoid subgroup in the Lowland East Cushitic family. The aim is to identify and describe the phonological similarities and differences that exist among these languages. The classification of the languages' sound systems, gemination, phonotactics and syllable structures are carried out in order to determine the major pattern of differences and similarities. Some major sound changes are discovered and the merger of voiced obstruents into voiceless counterparts is another major finding observed in these languages.
\end{abstract}

Keywords: Konsoid, comparison, inventory, constraint, syllable structure

\section{Introduction}

The Konsoid subgroup belongs to the Oromoid group in the Lowland East Cushitic family within the Cushitic super family in the Afro-Asiatic phylum. This subgroup was first established by Bender (1971:187). The subgroup consists of three members: Konso, Diraytata and Mosittacha.

The Konso people live in Konso district whereas the Diraasha and Mosiye people live in Diraashe district. These districts are located in Segen Area People's Zone within the Southern Nation, Nationalities and People's Regional State of the Federal Democratic Republic of Ethiopia. The Konso refer to their language by the name "Afa $\chi$ onso" whereas their neighbors and the linguistic literature refer to both the people and the language by the name Konso. In this paper, therefore, the name Konso is used to refer to both the people and the language. The Diraasha people refer to their language by the name Diraytata and the Mosiye people refer to their language by the name Mosittacha. The population of Konso is estimated to be 250,000 whereas the population of Diraasha and Mosiye are

\footnotetext{
* My deepest thanks are due to Professor Getahun Amare for his invaluable comments and suggestions. All errors and omissions are only mine.

${ }^{* *}$ Wondwosen Tesfaye: Associate Professor of Linguistics, Academy of Ethiopian Languages and Cultures, Addis Ababa University, Addis Ababa, Ethiopia. He is the author of the book The Grammar of Mosittacha. E-mail: wondwosen.tesfaye@aau.edu.et.
} 
estimated to be 142,558 and 19,628 respectively (Central Statistical Agency, 2008). The basic economic activity of the people is agriculture. They also raise animals.

In this paper, the phonologies of the three members will be compared in terms of their phonemes, gemination, phonotactics and syllable structures.

\section{The phonemes}

In this subpart, first we shall present the consonant and vowel phonemes of the members and then we shall compare the consonant and vowel phonemes of each member.

\subsection{Konso}

Konso consists of 21 consonant phonemes: four plain stops $/ \mathrm{p} /, / \mathrm{t} /, / \mathrm{k} /$ and $/ \mathrm{R} /$, four implosives $/ \mathrm{b} /, / \mathrm{d} /, / \mathrm{f} /$ and $/ \mathrm{G} /$, one affricate $/ \mathrm{t} /$, five fricatives $/ \mathrm{f} /, / \mathrm{s} /, / \mathrm{f} /, / \chi /$ and $/ \mathrm{h} /$, three nasals $/ \mathrm{m} /, / \mathrm{n} /$ and $/ \mathrm{n} /$, two liquids $/ \mathrm{l} /$ and $/ \mathrm{r} /$, and two glides $/ \mathrm{w} /$ and $/ \mathrm{j} /$. It is clearly observed that there are no voiced obstruents in Konso (cf. Ongaye, 2013:7).

Similarly, Konso has five short (i, e, a, o, and u) and five long vowels (ii, ee, aa, oo and uu). Both short and long vowels occur in word medial and final position. Short vowels in word final position are devoiced (cf. Ongaye, 2013:19).

\subsection{Diraytata}

Diraytata has 21 consonant phonemes. That is, four plain stops /p/, /t/, /k/ and / $/$ /, two implosives $/ \mathrm{b} /$, and $/ \mathrm{d} /$, one affricate $/ \mathrm{t} \mathrm{f} /$, three ejectives $/ \mathrm{t}^{\prime} /, / \mathrm{t} \mathrm{f}^{\prime} /$ and $/ \mathrm{k}^{\prime} /$, four fricatives $/ \mathrm{f} /$, $/ \mathrm{s} /, / \mathrm{S} /$ and $/ \mathrm{h} /$, three nasals $/ \mathrm{m} /, / \mathrm{n} /$ and $/ \mathrm{n} /$, two liquids $/ 1 /$ and $/ \mathrm{r} /$ and two glides $/ \mathrm{w} /$ and $/ \mathrm{j} /$ (cf. Sinkeneh, 1983).

Besides, it has five short (i, e, a, o, and u) and five long (ii, ee, aa, oo, and uu) vowels. Both short and long vowels occur in word-medial and word-final positions. In Diraytata, word-final short vowels with a low tone are merged with zero. With the exception of the short vowel $[\mathrm{u}]$, when it occurs in word final position with a low tone, it becomes a devoiced vocoid that can only be recognized by means of a lip rounding (cf. Hayward, 1981). This situation has attributed, in Diraytata, to the existence of many words with consonant clusters at a word-final position.

\subsection{Mosittacha}

Mosittacha has 20 consonant phonemes. That is, four plain stops /p/, /t/, /k/, and / $/$, two implosives $/ \mathrm{b} /$ and $/ \mathrm{d} /$, one affricate $/ \mathrm{t} \mathrm{f} /$, three ejectives $/ \mathrm{s}^{\prime} /, \mathrm{t} \mathrm{f} ' /$ and $/ \mathrm{k} \%$, four fricatives $/ \mathrm{f} /$, $/ \mathrm{s} /, / \mathrm{s} /$ and $/ \mathrm{h} /$, two nasals $/ \mathrm{m} /$ and $/ \mathrm{n} /$, two liquids $/ \mathrm{l} /$ and $/ \mathrm{r} /$ and two glides $/ \mathrm{w} /$ and $/ \mathrm{j} /$ (cf. Wondwosen, 2015).

In addition to the 20 consonant phonemes, Mosittacha has five short (i, e, a, o, and $\mathrm{u}$ ) and five long (ii, ee, aa, oo, and uu) vowels. Both short and long vowels occur in word medial and final positions. Moreover, short vowels with a low tone are devoiced (Harlow, 2016:56). 


\subsection{Comparison}

When we compare the phonemes in the three languages the following similarity can be observed among the members of the subgroup. The following seventeen phonemes are shared by all the three members: $\mathrm{p}, \mathrm{t}, \mathrm{k}, \mathrm{P}, \mathrm{b}, \mathrm{d}, \mathrm{f}, \mathrm{s}, \int, \mathrm{h}, \mathrm{t} \int \mathrm{m}, \mathrm{n}, \mathrm{l}, \mathrm{r}, \mathrm{w}$, and $\mathrm{j}$. Regarding the differences, Konso has two more implosives ( $f$ and $G$ ) which are absent both in Diraytata and Mosittacha. Moreover, Diraytata and Mosittacha have ejective sounds, which are absent in Konso. Konso has the phoneme $\chi$, which does not exist in either Diraytata or Mosittacha. Moreover, both Konso and Diraytata have the phoneme n, which is absent in Mosittacha.

So far, we have discussed the phonemes of the Konsoid languages. In the course of our discussion, we have seen the phonemic similarities and differences among the descended languages. The question is then what is the historical implication of such similarities and differences? This question will take us to the consideration of the phonemes of ProtoLowland East Cushitic (PLEC) language family from which the three languages were descended. Black (1974) reconstructs the following PLEC consonant phonemes: *b, *d, *t,

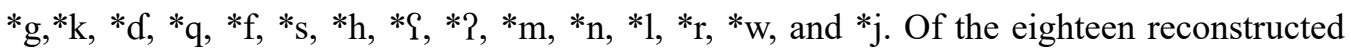
Proto- LEC phonemes the following thirteen phonemes have survived in all the three languages: t, k, $\mathrm{l}, \mathrm{d}, \mathrm{f}, \mathrm{s}, \mathrm{h}, \mathrm{m}, \mathrm{n}, \mathrm{l}, \mathrm{r}, \mathrm{w}$ and $\mathrm{j}$. Therefore, these phonemes are archaic phonemes which have survived in the present languages.

In the above PLEC consonant phonemes there are three voiced stops $/ \mathrm{b}, \mathrm{d}, \mathrm{g} /$ but these phonemes are absent in Konso, Diraytata and Mosittacha. This situation can probably tell us that the voiced stops in PLEC have been merged to the corresponding voiceless counterparts in the Konsoid languages. The merger of voiced stops into voiceless stops is a major sound change that has been observed in Konsoid languages. Hence, this change can be considered as Konsoid innovation.

Regarding the implosive consonants, Konso has four implosives: /b/, /d/, /f/ and /G/, whereas both Diraytata and Mosittacha have only two implosives: /6/ and /d/. When we consider the PLEC consonant phonemes, the only implosive sound found in the PLEC is /d/. This proto phoneme /d/ has survived in other Lowland East Cushitic languages such as Afar (Bliese, 1976), Bayso (Fleming, 1964), and Oromo (Black, 1974). Hence, the presence of the $/ 6 /$ in all the three languages can be considered as Konsoid innovation. Besides, the absence of $/ \mathrm{f} /$ and $/ \mathrm{G} /$ in both Diraytata and Mosittacha and their presence in Konso can be accounted for in terms of Konso innovation.

Coming to the ejective sounds, in the PLEC, consonant phonemes there is no ejective sound as such. However, the ejective sounds $/ \mathrm{t} / / \mathrm{t} \mathrm{f}^{\prime} /$ and $/ \mathrm{k} / \mathrm{exist}$ both in Diraytata and Mosittacha but absent in Konso. The presence of ejective sounds in Diraytata and 
Mosittacha can be considered as shared innovation.

The phoneme $/ \chi$ /exists only in Konso but is absent in both Diraytata and Mosittacha. It is also absent in PLEC. Thus, the presence of this phoneme in Konso can be considered as Konso innovation.

The phoneme $/ \mathrm{n} /$ which is absent in Proto- LEC is present in both Konso and Diraytata but it is absent in Mosittacha. This is also considered as shared innovation of Diraytata and Konso languages.

Regarding the vowel phonemes, the following similarities can be observed. In all the three members, there are five short and five long vowel phonemes which is a typical feature of the Cushitic vowel system (Mous, 2012). The other similarity is related to the distribution of vowels, and both short and long vowels occur in word-medial and word-final positions. The difference lies in the fact that in both Konso and Mosittacha, short vowels with a low tone are devoiced in word final positions. Short vowels with a low tone have been devoiced in Konso and Mosittacha, whereas in Diraytata word final short vowels with a low tone are merged with zero.

\section{Gemination}

Gemination is the cluster of two identical consonants. In this subpart we shall present gemination in each member and then we shall compare and contrast in order to find out the similarities and differences between members.

\subsection{Gemination in Konso}

In Konso, all consonants occur geminate. Geminate consonants occur only in a word-medial position. Geminate consonants in Konso function as ambisyllabic segments appearing as the coda of the preceding syllable and the onset of the following syllable (cf. Ongaye, 2013).

\subsection{Gemination in Diraytata}

In Diraytata with the exception of the phonemes $/ \mathrm{t}^{\prime} /, / \mathrm{t} \mathrm{f}^{\prime} /$ and $/ \mathrm{k}^{\prime} /$, all the other consonant phonemes occur geminate. In Diraytata geminate consonants may occur in word-medial or final positions. That is to say, they may occur in word-medial position as the coda of the preceding syllable and the onset of the following syllable as in the examples: $u k u k k a$ 'egg', and hib6a 'lips' or may occur in the word final position as in the examples, maff 'head' and mahh 'name' (cf. Sinkeneh, 1983).

\subsection{Gemination in Mosittacha}

In Mosittacha all consonant phonemes occur geminate except for the ejective phonemes $/ \mathrm{t} 5 \% / \mathrm{s} /$ and $/ \mathrm{k} \%$. Geminate consonants in Mosittacha occur as the coda of the preceding syllable and the onset of the following syllable (cf. Wondwosen, 2015: 21-24).

\subsection{Comparison}




\section{The Comparative Phonology of Konsoid}

When we compare geminate consonants in these three members of Konsoid subgroup, we can find the following differences among them. The first difference is that, in Konso, all consonants may occur geminates but in both Diraytata and Mosittacha, except for $/ \mathrm{s}^{\mathrm{s}} /, \mathrm{k} \%$, $/ \mathrm{t} /$ and $/ \mathrm{t} \mathrm{J}^{\prime} /$, all other consonants are found geminate.

The second difference is the fact that, in Konso and Mosittacha geminate consonants appear only in a word medial position. For example, maxxa 'name' in Konso and mahha 'name' in Mosittacha have the CVC-CV syllable structure. These examples show that geminate consonants in both Konso and Mosittacha can function as ambisyllabic segments appearing as the coda of the preceding syllable and the onset of the following syllable. Unlike in Konso and Mosittacha, geminate consonants in Diraytata may occur in word medial and final positions. For example, words such as hittina 'root' and ukukka 'egg' may demonstrate word medial germinate consonants whereas words such as mahh 'name' and masf 'head' may exemplify word final geminate consonants.

\section{Phonotactics}

In what follows, we shall present the distribution of non-geminate consonants in Konsoid.

\subsection{Phonotactics in Konso}

In Konso the following distribution of non-geminate consonants can be observed.

\subsubsection{Stops as the first member of a cluster}

Stops can occur as the first member of a cluster in Konso. Consider the following examples:

(1) a. sipla 'iron', ipsaa 'light', Gapnaa 'possession'

b. te? Saa 'elephant', da?ta 'butter', ki?saa 'fireplace'

c. ekta 'tail', dikla 'elbow', takma 'honey'

As can be seen from the above examples, in (1a), /p/ occurs preceding /1/ in sipla, preceding /s/ in ipsaa and preceding /n/ in Gapnaa. In (1b), / $/$ / occurs preceding $/ \mathrm{J} /$ in te? $\int a a$, preceding /t/ in da?ta and preceding /s/ in ki?saa. In (1c), /k/ occurs preceding /t/ in ekta, preceding /1/ in dikla and preceding $/ \mathrm{m} /$ in takma. However, in Konso a non-geminate cluster of stops cannot be followed by an affricate or an approximant. Moreover, two non-identical stops can occur as a cluster in Konso. This can be learned from the examples in (2) below.

(2) sata?ta 'lung', apteenta 'snow', ekta 'tail'

From the examples in (2), we can learn that in Konso, two different stops occur in a cluster. That is, in the cluster of consonants in the word sata?ta, the first member of the cluster is $/ 2 /$ and the second member is $/ t /$. Similarly, in the cluster of consonants in the word apteenta, the first member of the cluster is $/ \mathrm{p} /$ and the second member is $/ \mathrm{t} /$. When a 


\section{Wondwosen Tesfaye}

non-geminate cluster of stops occur, the first member of the cluster is either a voiceless glottal stop or a voiceless bilabial stop, and the second member is a voiceless alveolar stop (cf. Ongaye, 2013:23).

\subsubsection{Implosives as the first member of a cluster}

Implosives can occur as the first member in a non-geminate cluster as the examples in (3) show.

(3) habta 'boarder', mudkahanta 'tree species', loG'ta 'leg, foot', JoloG'loGitta 'claw'

In (3), /6/ occurs receding /t/ in habta, /d / occurs preceding /k/ in mudkahanta. /G/ occurs preceding /t/ and /1/ in loGta and Sologlogitta respectively.

\subsubsection{Fricatives as the first member of a cluster}

Konso has a non-geminate cluster of consonants where the first member of the cluster is a fricative and the second member is a stop. Consider the examples below:

(4) lafta 'bone', kurruuffaa 'droppings (sheep or goat)', napahta 'ear', koskorta 'partridge', $k o \int k o \int a$ 'comb (of chicken, bird)'

In (4), /f/ occurs preceding /t/ and / $/$ / in lafta and kurruuffaa respectively. Similarly, /h/ occurs preceding /t/ in napahta, /s/ occurs preceding / $/ \mathrm{k} /$ in koskorta, and $/ \mathrm{J} /$ occurs preceding $/ \mathrm{k} /$ in $k o \int k o f a$. In such a cluster, the second member of the cluster can be either $/ \mathrm{t} /$ or $/ \mathrm{k} /$ or $/ \mathrm{J} /$. Moreover, in Konso, fricatives can be followed by a nasal. This is shown in example (5):

(5) moxna 'rocky area', pahnaa 'example', pohmojta 'chameleon'

In (5), the first members of the clusters are fricatives and the second members are nasals. However, in Konso fricatives cannot be followed by affricates, liquids or approximants in a non-geminate cluster.

\subsubsection{Nasals as the first member of a cluster}

Nasals can be followed by stops, implosives and fricatives in a non-geminate cluster. The following are examples:

(6) a. kanta 'neighbor', taamta 'branch', dankaa 'throat', tampoota 'tobacco'

b. hanfuftaa 'saliva', hanGaraara 'caterpillar', sinda 'urine'

c. konfa 'short', komfa 'short (for cloth)', dansa 'dance'

In (6a), the first members of the clusters are nasals and the second members are stops. In (6b), the first members are nasals and the second members are implosives. In (6c), the first members of the clusters are nasals and the second members are fricatives.

4.1.5 Lateral as the first member of a cluster

A lateral can be followed by stops, implosives, fricatives and nasals in a non-geminate cluster of consonants. This can be learned from the examples in (7):

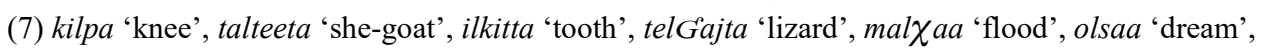
xolmaa 'neck' 


\section{The Comparative Phonology of Konsoid}

In (7), $/ 1 /$ occurs preceding stops, preceding $/ \mathrm{G} /$, preceding $/ \chi /$, preceding $/ \mathrm{s} /$, and preceding $/ \mathrm{m} /$ in a non-geminate cluster. But in Konso, there is no non-geminate cluster where the first member is a lateral and the second member is an approximant. Moreover, in Konso, there is no non-geminate cluster where the first member is a lateral and the second member is an affricate.

4.1.6 Flaps as the first member of a cluster

A flap can be followed by stops, implosives, fricatives and nasals in non-geminate cluster.

(8) arpa 'elephant', farta 'horse', murkufaa 'fish', sarbaa 'calf', tardaa 'ash', furfaa 'baby's feces',

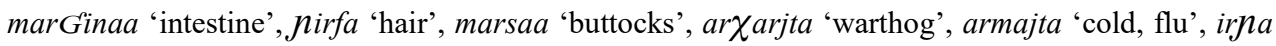
'gum'

In (8), the flap / $\mathrm{r}$ / occurs preceding stops, implosives, fricatives and nasals.

4.1.7 Glides as a first member of a cluster

Glides can be followed by stops, fricatives, nasals and liquids. This can be observed from the following examples:

(9) a. kawpa 'besides', kawkawa 'jaw', tawna 'bell', kawsa 'chin', hawla 'grave'

b. ajkitta 'grass', orajta 'hynea', xajne?taa 'thread', ojra 'tree', kajlaa 'tassel'

In (9a), the first member of the cluster is /w/ and the second members are stops, a nasal, a fricative and a lateral respectively. In (9b) the first member of the cluster is $/ \mathrm{j} /$ and the second members are stops, nasals and liquids.

It is apparent from the foregoing that a consonant sequence in Konso is made up of two non-geminate consonants. Consonant sequences only occur word-medially. Hence, consonant sequences in Konso can be analyzed as the coda of the preceding syllable and the onset of the following syllable. From the preceding discussion, we have seen that in Konso, consonants that occur in the coda position as the first member of the sequences are stops, fricatives, nasals, liquids and approximants. The following phonotactic grid can be made for Konso.

As it can be observed from Table 1, all consonants do not make a cluster in Konso. There are restrictions on the sequence of many consonants. That is to say, there are many consonants in Konso that do not make a cluster. In Konso, stops can be followed by another stop, fricatives, nasals and liquids. The voiceless bilabial stop /p/ allows /t/, /s/, /n/ and $/ 1 /$ as its second members in a sequence. Similarly, the voiceless velar stop $/ \mathrm{k} /$ allows $/ \mathrm{t} /$, $/ \mathrm{m} /$ and $/ 1 /$ as its second member in a cluster. Stops do not allow as a second member implosives, the affricate or glides in a cluster. 
Wondwosen Tesfaye

Table 1. Phonotactic grid of Konso

\begin{tabular}{|c|c|c|c|c|c|c|c|c|c|c|c|c|c|c|c|c|c|c|c|c|c|c|}
\hline & \multicolumn{5}{|c|}{ Stops } & \multicolumn{4}{|c|}{ Implosives } & \multicolumn{5}{|c|}{ Fricatives } & \multirow{2}{*}{$\frac{\text { Aff. }}{\mathrm{t} \int}$} & \multicolumn{3}{|c|}{ Nasals } & \multicolumn{2}{|c|}{ Liquids } & \multicolumn{2}{|c|}{ Glides } \\
\hline & & $\mathrm{p}$ & $\mathrm{t}$ & $\mathrm{k}$ & $?$ & 6 & d & f & G & $\mathrm{f}$ & $\mathrm{s}$ & $\int$ & $\chi$ & $\mathrm{h}$ & & $\mathrm{m}$ & $\mathrm{n}$ & $\mathrm{n}$ & 1 & $\mathrm{r}$ & $\mathrm{w}$ & $\mathrm{j}$ \\
\hline \multirow{4}{*}{ Stops } & $\mathrm{p}$ & - & $\mathrm{x}$ & - & - & - & - & - & - & - & $\mathrm{x}$ & - & - & - & - & - & $\mathrm{x}$ & - & $\mathrm{x}$ & - & - & - \\
\hline & $\mathrm{t}$ & - & - & - & - & - & - & - & - & - & - & - & - & - & - & - & - & - & - & - & - & - \\
\hline & $\mathrm{k}$ & - & $\mathrm{x}$ & - & - & - & - & - & - & - & - & - & - & - & - & $\mathrm{x}$ & - & - & $\mathrm{x}$ & - & - & - \\
\hline & ? & - & $\mathrm{x}$ & - & - & - & - & - & - & - & - & $\mathrm{x}$ & - & - & - & - & - & - & - & - & - & - \\
\hline \multirow{4}{*}{ Implosives } & 6 & - & $\mathrm{x}$ & - & - & - & - & - & - & - & - & - & - & - & - & - & - & - & $\mathrm{x}$ & - & - & - \\
\hline & d & - & $\mathrm{x}$ & $\mathrm{x}$ & - & - & - & - & - & - & - & - & - & - & - & - & - & - & - & - & - & - \\
\hline & f & - & - & - & - & - & - & - & - & - & - & - & - & - & - & - & - & - & - & - & - & - \\
\hline & G & - & $\mathrm{x}$ & - & - & - & - & - & - & - & - & - & - & - & - & - & - & - & $\mathrm{x}$ & - & - & - \\
\hline \multirow{5}{*}{ Fricatives } & $\mathrm{f}$ & - & $\mathrm{x}$ & - & - & - & - & - & - & - & - & - & - & - & - & - & - & - & - & - & - & - \\
\hline & $\mathrm{s}$ & - & - & $\mathrm{x}$ & - & - & - & - & - & - & - & - & - & - & - & - & - & - & - & - & - & - \\
\hline & $\int$ & - & - & $\mathrm{x}$ & - & - & - & - & - & - & - & - & - & - & - & - & - & - & - & - & - & - \\
\hline & $\chi$ & - & - & - & - & - & - & - & - & - & - & - & - & - & - & - & $\mathrm{x}$ & - & - & - & - & - \\
\hline & $\mathrm{h}$ & - & $\mathrm{x}$ & - & - & - & - & - & - & - & - & - & - & - & - & $\mathrm{x}$ & $\mathrm{x}$ & - & - & - & - & - \\
\hline Aff. & $\mathrm{t} \int$ & - & - & - & - & - & - & - & - & - & - & - & - & - & - & - & - & - & - & - & - & - \\
\hline \multirow{3}{*}{ Nasals } & $\mathrm{m}$ & $\mathrm{x}$ & $\mathrm{x}$ & - & - & - & - & $\mathrm{x}$ & - & - & - & - & - & - & - & - & - & - & - & - & - & - \\
\hline & $\mathrm{n}$ & - & $\mathrm{x}$ & $\mathrm{x}$ & - & - & $\mathrm{x}$ & - & $\mathrm{x}$ & $\mathrm{x}$ & $\mathrm{x}$ & $\mathrm{x}$ & - & - & - & - & - & - & - & - & - & - \\
\hline & $\mathrm{n}$ & - & - & - & - & - & - & - & - & - & - & - & - & - & - & - & - & - & - & - & - & - \\
\hline \multirow{2}{*}{ Liquids } & 1 & $\mathrm{x}$ & $\mathrm{x}$ & $\mathrm{x}$ & - & - & - & - & $\mathrm{x}$ & - & $\mathrm{x}$ & - & $\mathrm{x}$ & - & - & $\mathrm{x}$ & - & - & - & - & - & - \\
\hline & $\mathrm{r}$ & $\mathrm{x}$ & $\mathrm{x}$ & $\mathrm{x}$ & & - & $\mathrm{x}$ & $\mathrm{x}$ & $\mathrm{x}$ & $\mathrm{x}$ & - & $\mathrm{x}$ & - & - & - & $\mathrm{x}$ & - & $\mathrm{x}$ & - & - & - & - \\
\hline \multirow{2}{*}{ Glides } & w & $\mathrm{x}$ & - & $\mathrm{x}$ & - & - & - & - & - & - & $\mathrm{x}$ & - & - & - & - & - & $\mathrm{x}$ & - & $\mathrm{x}$ & - & - & - \\
\hline & $\mathrm{j}$ & - & $x$ & $\mathrm{x}$ & - & - & - & - & - & - & - & - & - & - & - & - & $\mathrm{x}$ & - & $\mathrm{x}$ & $\mathrm{x}$ & - & - \\
\hline
\end{tabular}

Implosives allow stops and liquids as the second member in a cluster. The implosive /6/, for example, allows $/ \mathrm{t} /$ and $/ \mathrm{l} / \mathrm{as}$ a second member in a sequence. The implosive / $\mathrm{d} /$ allows $/ \mathrm{t} /$ and $/ \mathrm{k} /$ as its second member in a cluster. The implosive $/ \mathrm{G} /$ allows $/ \mathrm{t} /$ and $/ \mathrm{l} /$ as its second member in a sequence. However, $/ \mathfrak{f} /$ does not allow any consonant as its second member. Moreover, implosives do not allow other implosives, fricatives, affricates, nasals and glides as the second member in a cluster.

Fricatives can be followed by stops and nasals in a non-geminate cluster. The phoneme /f/ can only be followed by $/ \mathrm{t} /$ in a non-geminate cluster. $/ \mathrm{s} /$ can only be followed by $/ \mathrm{k} /$ in a non-geminate sequence. $/ \mathrm{J} / \mathrm{can}$ only be followed by $/ \mathrm{k} /$ in a non-geminate cluster. $/ \chi /$ can only be followed by $/ \mathrm{n} /$ in a sequence. $/ \mathrm{h} /$ can be followed by $/ \mathrm{t} /, \mathrm{m} / \mathrm{and} / \mathrm{n} /$. However, fricatives do not allow implosives, other fricatives, the affricate, liquids or glides as the 


\section{The Comparative Phonology of Konsoid}

second member in a non-geminate cluster.

The affricate in Konso does not occur whether as the first or second member of a non-geminate cluster. In other words, the affricate does not make any kind of consonant cluster at all.

Nasals can be followed by stops, implosives and fricatives. $/ \mathrm{m} /$ can be followed $/ \mathrm{p} /$, $/ \mathrm{t} /$ and $/ \mathrm{f} /$. Similarly, $/ \mathrm{n} /$ can be followed by $/ \mathrm{t} /, / \mathrm{k} /, / \mathrm{d} / /, / \mathrm{G} /, / \mathrm{f} /, / \mathrm{s} /$ and $/ \mathrm{f} /$. However, the affricate, liquids and glides are not in general allowed to occur as the second member of such a cluster.

Liquids can have more consonants as the second member as compared to the previous classes. They allow stops, implosives, fricatives, and nasals to occur as the second member in a cluster. $/ 1 /$ allows $/ \mathrm{p} /, / \mathrm{t} /, / \mathrm{k} /, / \mathrm{G} /, / \mathrm{s} /, / \mathrm{g} /$ and $/ \mathrm{m} /$ as its second member. By the same token, $/ \mathrm{r} /$ allows $/ \mathrm{p} /, / \mathrm{t} /, / \mathrm{k} /, / \mathrm{d} /, / \mathrm{f} /, / \mathrm{G} /, / \mathrm{f} /, / \mathrm{J} /, / \mathrm{m} /$ and $/ \mathrm{j} /$ as its second member in a cluster.

Glides can be followed by stops, fricatives, nasals and liquids. /w/ can be followed by /p/, $/ \mathrm{k} /, / \mathrm{s} /, / \mathrm{n} /$ and $/ \mathrm{l} /$ as its second member in a cluster. $/ \mathrm{j} /$ allows $/ \mathrm{t} /, / \mathrm{k} /, / \mathrm{n} /, / 1 /$ and $/ \mathrm{r} /$ as its second member in a cluster.

From the preceding discussion, we can observe that sonorants allow more consonant clusters than obstruents. This is because obstruents allow four different classes (i.e. stops, fricatives, nasals and liquids) as the second member in a non-geminate cluster whereas sonorants allow five classes (i.e. stops, implosives, fricatives, nasals and liquids) as the second member in a cluster.

\subsection{Phonotactics in Diraytata}

Diraytata allows a maximum of two-consonant clusters. In what follows, we shall present possible cluster of non-geminate consonants and the constraint applied to consonant sequencing.

4.2.1 Fricatives as the first member of a cluster

Fricatives can be followed by stops and nasals in a cluster of non-geminate consonants. The following are examples:

(10) a. laft 'bone', iskatt 'woman' b. ufnaad 'know'

In (10a), the first members of the clusters are the fricatives /f/ and /s/ and the second members are the stops $/ \mathrm{t} /$ and $/ \mathrm{k} /$. In (10b), the first member of the cluster is the $/ \mathrm{f} /$ and the second member is $/ \mathrm{n} /$.

\subsubsection{Nasals as a first member of a cluster}

Nasals can be followed by stops, implosives and fricatives. Consider the examples below.

(11) a. hampira 'bird', inant 'girl', inkot 'mother'

b. amb 'breast', hund 'ten' 
c. famfajja 'ladder', hons 'hippopotamus', in far 'younger brother'

In (11a), the first members of the cluster are nasals and the second members are stops. In (11b), the first members of the cluster are nasals and the second members are implosives. Similarly, in (11c), the first members of the cluster are nasals and the second members are fricatives.

4.2.3 Lateral as the first member of a cluster

The lateral can be followed by stops, implosives, ejectives, fricatives and nasals as illustrated in the following examples:

(12) a. kilp 'knee', ilt 'eye', dilk 'elbow'

b. uldat 'late afternoon'

c. pulk'ant 'dust'

d. hols 'laugh', helf 'shiver (from cold)', dilha 'charcoal'

e. ilmama 'tears'

In (12a), the lateral / / in Diraytata is followed by stops, in (12b), it is followed by implosive, in (12c), it is followed by ejective, in (12d), it is followed by fricatives and in (12e), it is followed by a nasal as a second member of the consonant cluster.

4.2.4 Flap as the first member of a cluster

The flap can be followed by stops, implosives, ejectives, fricatives and nasals. Consider the examples in (13):

(13) a. arp 'elephant', diirt 'male', hark 'hand'

b. merda 'thick', firt $\int$ 'a 'diarrhea'

c. irfet 'wooden part of oxen drown plow', kors 'advise', parfot 'local beer', harharajt 'warthog'

d. korma 'male (animal)', korna 'a type of snake'

In (13a), the flap / $r$ / is followed by stops, in (13b), it is followed by implosive and ejective, in (13c), it is followed by fricatives and in (13d), it is followed by nasals.

4.2.5 Bilabial glide as the first member of a cluster

The bilabial glide /w/ is followed by fricatives and laterals as can be observed from the following examples:

(14) a. kaws 'chin', aw fitt 'new'

b. howlet 'molar tooth', pawra 'two-bladed digging stick'

In (14a), the bilabial glide /w/ is followed by fricatives and in (14b), it is followed by liquids.

4.2.6 Palatal glide as the first member of a cluster

The palatal glide $/ \mathrm{j} /$ is followed by stops, implosives, ejectives, fricatives, nasals and liquids. This is shown in the following examples:

(15) a. hajpaat 'bride', orajt 'hyena', kajkajja 'type of grass', aj ?ajt 'small hairs on body (special on 


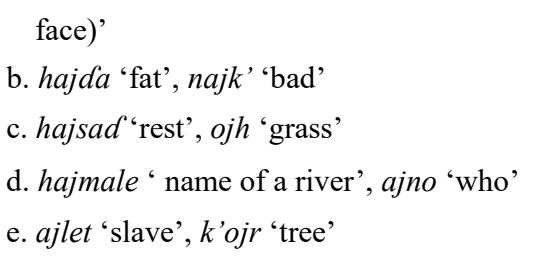

In (15a), the palatal glide $/ \mathrm{j} /$ is followed by stops, in $(15 b)$ it is followed by an implosive and an ejective, in (15c) it is followed by fricatives, in (15d) it is followed by nasals and in $(15 \mathrm{e})$ it is followed by liquids.

From the preceding discussion on the consonant sequences of Diraytata, we can argue that in Diraytata, consonant sequences are made up of only two non-geminate consonants. Moreover, in Diraytata a non-geminate consonant sequence can be analyzed either as the coda of the first syllable and onset of the following syllable or as the coda of the final syllable. In Diraytata, consonants that occur as the first member in the sequence are fricatives, nasals, liquids and glides. The consonant clusters in Diraytata can be summarized in the following phonotactic grid.

As can be observed from Table 2, in Diraytata, all consonants do not make clusters. There are restrictions on making sequences of non-geminate consonants. For example, we cannot find a non-geminate cluster of consonants in Diraytata where the first member of a cluster is a stop, an implosive, an ejective or an affricate.

Fricatives can be followed by stops and nasals in a non-geminate consonant cluster, but such sequences are restricted to /f/ being followed by $/ \mathrm{t} /$ and $/ \mathrm{n} /$. Besides, $/ \mathrm{s} /$ is followed by $/ \mathrm{k} /$ in a non-geminate cluster. Any sequences of consonants other than these are not allowed.

Nasals can be followed by stops, implosives and fricatives as the second member in a non-geminate consonant cluster. For instance, $/ \mathrm{m} /$ allows $/ \mathrm{p} /, / 6 /$ and $/ \mathrm{f} /$ as the second member in a non-geminate cluster of consonants. Similarly, /n/ allows $/ \mathrm{t} /, / \mathrm{k} /, / 6 /$, /s/ and $/ \mathrm{J} /$ as the second member in a non-geminate consonant cluster. Nasals do not allow ejectives, liquids or glides as their second member in a non-geminate consonant cluster.

Liquids allow more consonants as the second member in a non-geminate cluster as compared to other classes. Hence, liquids can be followed by stops, implosives, ejectives, fricatives and nasals in a non-geminate consonant cluster. The lateral $/ 1 /$, for example, allows $/ \mathrm{p} /, / \mathrm{t} /, / \mathrm{k} /, / 6 /, / \mathrm{k}^{\prime} /, / \mathrm{s} /, / \mathrm{J} /, / \mathrm{h} /$ and $/ \mathrm{m} /$ as the second member in a non-geminate cluster. On the other hand, the flap /r/ allows /p/, /t/, /k/, /d/, /tf'/, /f/, /s/, / $/$, /h/, /m/ and /n/ as the second member in a non-geminate cluster.

Glides can be followed by stops, implosives, ejectives, fricatives, nasals and liquids. The bilabial glide $/ \mathrm{w} /$ allows $/ \mathrm{s} /, / \mathrm{J} /, / 1 /$ and $/ \mathrm{r} /$ as the second member in a non-geminate cluster. 
Moreover, the palatal glide $/ \mathrm{j} /$ allows $/ \mathrm{p} /, / \mathrm{t} /, / \mathrm{k} /, / \mathrm{l} /, / \mathrm{d} /, / \mathrm{k} /, / \mathrm{s} /, / \mathrm{h} /, / \mathrm{m} /, / \mathrm{n} /, / 1 /$ and $/ \mathrm{r} /$ as the second member of a non-geminate cluster.

Table 2. Phonotactic grid of Diraytata

\begin{tabular}{|c|c|c|c|c|c|c|c|c|c|c|c|c|c|c|c|c|c|c|c|c|c|c|}
\hline & \multicolumn{5}{|c|}{ Stops } & \multicolumn{2}{|c|}{ Impl } & \multicolumn{3}{|c|}{ Eje. } & \multicolumn{4}{|c|}{ Fric. } & \multirow{2}{*}{$\frac{\text { Aff. }}{\mathrm{t} \int}$} & \multicolumn{3}{|c|}{ Nasals } & \multicolumn{2}{|c|}{ Liq. } & \multicolumn{2}{|c|}{ Glides } \\
\hline & & $\mathrm{p}$ & $\mathrm{t}$ & $\mathrm{k}$ & $?$ & 6 & d & $t^{\prime}$ & t ${ }^{\prime}$ & $\mathrm{k}^{\prime}$ & $\mathrm{f}$ & $\mathrm{s}$ & $\int$ & $\mathrm{h}$ & & $\mathrm{m}$ & $\mathrm{n}$ & $\mathrm{n}$ & 1 & $\mathrm{r}$ & $\mathrm{w}$ & $\mathrm{j}$ \\
\hline \multirow{4}{*}{ Stops } & $\mathrm{p}$ & - & - & - & - & - & - & - & - & - & - & - & - & - & - & - & - & - & - & - & - & - \\
\hline & $\mathrm{t}$ & - & - & - & - & - & - & - & - & - & - & - & - & - & - & - & - & - & - & - & - & - \\
\hline & $\mathrm{k}$ & - & - & - & - & - & - & - & - & - & - & - & - & - & - & - & - & - & - & - & - & - \\
\hline & $?$ & - & - & - & - & - & - & - & - & - & - & - & - & - & - & - & - & - & - & - & - & - \\
\hline \multirow{2}{*}{ Impl. } & 6 & - & - & - & - & - & - & - & - & - & - & - & - & - & - & - & - & - & - & - & - & - \\
\hline & d & - & - & - & - & - & - & - & - & - & - & - & - & - & - & - & - & - & - & - & - & - \\
\hline \multirow{3}{*}{ Eje. } & $\mathrm{t}^{\prime}$ & - & - & - & - & - & - & - & - & - & - & - & - & - & - & - & - & - & - & - & - & - \\
\hline & $\mathrm{t} \int{ }^{\prime}$ & - & - & - & - & - & - & - & - & - & - & - & - & - & - & - & - & - & - & - & - & - \\
\hline & k' & - & - & - & - & - & - & - & - & - & - & - & - & - & - & - & - & - & - & - & - & - \\
\hline \multirow{4}{*}{ Fric. } & $\mathrm{f}$ & - & $\mathrm{x}$ & - & - & - & - & - & - & - & - & - & - & - & - & - & $\mathrm{x}$ & - & - & - & - & - \\
\hline & $\mathrm{s}$ & - & - & $\mathrm{x}$ & - & - & - & - & - & - & - & - & - & - & - & - & - & - & - & - & - & - \\
\hline & $\int$ & - & - & - & - & - & - & - & - & - & - & - & - & - & - & - & - & - & - & - & - & - \\
\hline & $\mathrm{h}$ & - & - & - & - & - & - & - & - & - & - & - & - & - & - & - & - & - & - & - & - & - \\
\hline Aff. & $\mathrm{t} \int$ & - & - & - & - & - & - & - & - & - & - & - & - & - & - & - & - & - & - & - & - & - \\
\hline \multirow{3}{*}{ Nasals } & $\mathrm{m}$ & $\mathrm{x}$ & - & - & - & $\mathrm{x}$ & - & - & - & - & $\mathrm{x}$ & - & - & - & - & - & - & - & - & - & - & - \\
\hline & $\mathrm{n}$ & - & $\mathrm{x}$ & $\mathrm{x}$ & - & - & $\mathrm{x}$ & - & - & - & - & $\mathrm{x}$ & $\mathrm{x}$ & - & - & - & - & - & - & - & - & - \\
\hline & $\mathrm{n}$ & - & - & - & - & - & - & - & - & - & - & - & - & - & - & - & - & - & - & - & - & - \\
\hline \multirow{2}{*}{ Liquids } & 1 & $\mathrm{x}$ & $\mathrm{x}$ & $\mathrm{x}$ & - & - & $\mathrm{x}$ & - & - & $\mathrm{x}$ & - & $\mathrm{x}$ & $\mathrm{x}$ & $\mathrm{x}$ & - & $\mathrm{x}$ & - & - & - & - & - & - \\
\hline & $\mathrm{r}$ & $\mathrm{x}$ & $\mathrm{x}$ & $\mathrm{x}$ & & - & $\mathrm{x}$ & & $\mathrm{x}$ & - & $\mathrm{x}$ & $\mathrm{x}$ & $\mathrm{x}$ & $\mathrm{x}$ & - & $\mathrm{x}$ & $\mathrm{x}$ & - & - & - & - & - \\
\hline \multirow{2}{*}{ Glides } & $\mathrm{w}$ & - & - & - & - & - & - & - & - & - & - & $\mathrm{x}$ & $\mathrm{x}$ & - & - & - & - & - & $\mathrm{x}$ & $\mathrm{x}$ & - & - \\
\hline & $\mathrm{j}$ & $\mathrm{x}$ & $\mathrm{x}$ & $\mathrm{x}$ & $\mathrm{x}$ & - & $\mathrm{x}$ & - & - & $\mathrm{x}$ & - & $\mathrm{x}$ & - & $\mathrm{x}$ & - & $\mathrm{x}$ & $\mathrm{x}$ & - & $\mathrm{x}$ & $\mathrm{x}$ & - & - \\
\hline
\end{tabular}

Generally speaking, in Diraytata, sonorants allow more consonant clusters than obstruents. This is because obstruents allow in sequences of consonants as the second member from two classes (i.e. stops and nasals) whereas sonorants allow sequences of consonants as the second member from six classes (i.e. stops, implosives, ejectives, fricatives, nasals and liquids).

\subsection{Phonotactics in Mosittacha}

Mosittacha allows non-geminate consonant clusters. A consonant cluster occurs in word-medial position. In what follows we shall present the details.

4.3.1 Fricatives as the first member of a cluster 


\section{The Comparative Phonology of Konsoid}

Fricatives can be followed by stops, affricates, nasals and liquids in a cluster of non-geminate consonants. The following are examples.

(16) a. kaska 'shoulder', dus ?e 'kidney'

b. t fuft fa 'back'

c. masmasoont fa 'rejoice'

d. sihla 'iron'

In (16a), the voiceless alveolar /s/ is followed by stops, in (16b), the voiceless labiodental fricative $/ \mathrm{f} /$ is followed by the affricate $/ \mathrm{t} /$, in (16c), the voiceless alveolar fricative $/ \mathrm{s} /$ is followed by the bilabial nasal $/ \mathrm{m} /$ and in (16d) it is followed by the lateral $/ 1 /$.

4.3.2 Nasals as the first member of a cluster

Nasals can be followed by stops, implosives and fricatives. The following are examples:

(17) a. hampirta 'bird', funtuko 'owl', inkot fa 'mother'

b. amba 'breast', honda 'love'

c. s'ink'a 'grass'

d. puttumsa 'be white', in fara 'young brother', nanho 'shame'

e. rifantfa 'hair'

In examples (17a), nasals are followed by stops, in (17b) nasals are followed by implosives, in (17c) the nasal is followed by an ejective, in (17d) nasals are followed by fricatives and in (17e), the nasal is followed by an affricate.

4.3.3 Lateral as the first member of a cluster

The lateral can be followed by stops, ejectives, fricatives, affricates and nasals. This can be learned from the examples in (18):

(18) a. kilpa 'knee', mkeltajtfa 'baboon', kolkoltfa 'young'

b. talk'ajtfitfa 'lizard'

c. holsina 'laugh', kalfuma 'west', silha 'iron'

d. tfaltfet fa 'she-goat'

e. kalmat fa 'dwell'

In (18a), the lateral /1/ is followed by stops, in (18b) it is followed by an ejective, in (18c) it is followed by fricatives, in (18d) it is followed by an affricate and in (18e) it is followed by a nasal.

4.3.4 Flap as the first member of a cluster

The flap can be followed by stops, ejectives, fricatives, affricate and nasals as shown in (19):

(19) a. harka 'hand', kar?a 'abdomen'

b. dark'o 'small intestine'

c. narfetfa 'needle', horsina 'tease', harharo 'warthog'

d. diirtfa 'male' 
e. karma 'lion'

In (19a) the flap /r/ is followed by stops, in (19b) it is followed by an ejective, in (19c) it is followed by fricatives, in (19d) it is followed by an affricate and in (19e) it is followed by nasals.

\subsubsection{Glides as the first member of a cluster}

Glides can be followed by stops, implosives, ejectives, fricatives, affricate, nasals and laterals. The following are illustrative examples.

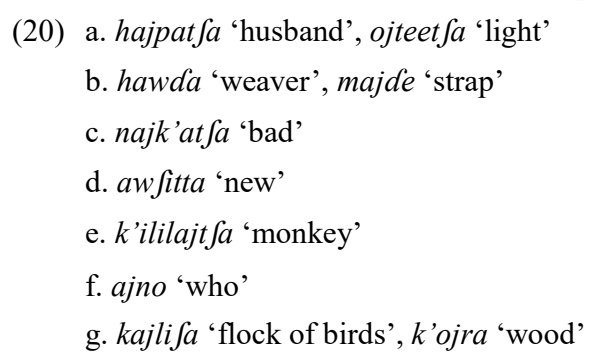

In (20a), the palatal glide / $\mathrm{j} /$ is followed by stops, in (20b) the bilabial and palatal glides are followed by implosives, in (20c) the palatal glide $/ \mathrm{j} /$ is followed by an ejective, in (20d) the bilabial glide / $\mathrm{w} /$ is followed by a fricative, in (20e) the palatal glide $/ \mathrm{j} /$ is followed by an affricate, in (20f) the palatal glide is followed by a nasal and in $(20 \mathrm{~g})$ the palatal glide /j/ is followed by liquids.

So far, we have seen the clusters of non-geminate consonants in Mosittacha. From the presentation so far, we have seen that the consonants that come first in a cluster are fricatives, nasals, liquids and glides. The following phonotactic grid table may summarize the permissible and impermissible sequences of consonants.

As can be observed from Table 3, in Mosittacha all consonants do not make a cluster. There are restrictions in making sequences of non-geminate consonant clusters. For example, we cannot find a non-geminate cluster of consonants in Mosittacha where the first member of a cluster is a stop, an implosive, an ejective or an affricate.

Fricatives can be followed by stops, the affricate and nasals in a non-geminate consonant cluster, but such sequences are restricted to the voiceless labiodental fricative /f/ being followed by the affricate $/ \mathrm{t} \mathrm{f} /$. The voiceless alveolar fricative $/ \mathrm{s} / \mathrm{can}$ be followed by $/ \mathrm{k} /, \mathrm{h} /$ and $/ \mathrm{m} /$. Besides, $/ \mathrm{h} /$ can be followed by $/ 1 /$ in a non-geminate cluster. Any sequences of consonants other than these are not allowed.

Nasals can be followed by stops, implosives, ejectives, fricatives and affricate as the second member in a non-geminate consonant cluster. The bilabial nasal $/ \mathrm{m} /$, for example, allows $/ \mathrm{p} /, / 6 /, / \mathrm{k} /, / \mathrm{J} /, / \mathrm{h} /, / \mathrm{t} / \mathrm{as}$ the second member in a non-geminate cluster of consonants. Similarly, the alveolar nasal $/ \mathrm{n} /$ allows $/ \mathrm{t} /, / \mathrm{k} /, / \mathrm{d} /, / \mathrm{s} /$ and $/ \mathrm{s} /$ as the second member in a non-geminate consonant cluster. Nasals do not allow liquids or glides as the 
second member in a non-geminate consonant cluster.

Table 3. Phonotactic grid of Mosittacha

\begin{tabular}{|c|c|c|c|c|c|c|c|c|c|c|c|c|c|c|c|c|c|c|c|c|c|}
\hline & \multicolumn{5}{|c|}{ Stops } & \multicolumn{2}{|c|}{ Impl } & \multicolumn{3}{|c|}{ Eje. } & \multicolumn{4}{|c|}{ Fric. } & \multirow{2}{*}{$\frac{\text { Affr. }}{t \int}$} & \multicolumn{2}{|c|}{ Nasals } & \multicolumn{2}{|c|}{ Liq. } & \multicolumn{2}{|c|}{ Glides } \\
\hline & & $\mathrm{p}$ & $\mathrm{t}$ & $\mathrm{k}$ & $?$ & 6 & $d$ & $t^{\prime}$ & t ${ }^{\prime}$ & $\mathrm{k}^{\prime}$ & $\mathrm{f}$ & $\mathrm{s}$ & $\int$ & $\mathrm{h}$ & & $\mathrm{m}$ & $\mathrm{n}$ & 1 & $\mathrm{r}$ & $\mathrm{w}$ & $\mathrm{j}$ \\
\hline \multirow{4}{*}{ Stops } & $\mathrm{p}$ & - & - & - & - & - & - & - & - & - & - & - & - & - & - & - & - & - & - & - & - \\
\hline & $\mathrm{t}$ & - & - & - & - & - & - & - & - & - & - & - & - & - & - & - & - & - & - & - & - \\
\hline & $\mathrm{k}$ & - & - & - & - & - & - & - & - & - & - & - & - & - & - & - & - & - & - & - & - \\
\hline & $?$ & - & - & - & - & - & - & - & - & - & - & - & - & - & - & - & - & - & - & - & - \\
\hline \multirow{2}{*}{ Impl. } & 6 & - & - & - & - & - & - & - & - & - & - & - & - & - & - & - & - & - & - & - & - \\
\hline & d & - & - & - & - & - & - & - & - & - & - & - & - & - & - & - & - & - & - & - & - \\
\hline \multirow{3}{*}{ Eje. } & $\mathrm{t}^{\prime}$ & - & - & - & - & - & - & - & - & - & - & - & - & - & - & - & - & - & - & - & - \\
\hline & ts' & - & - & - & - & - & - & - & - & - & - & - & - & - & - & - & - & - & - & - & - \\
\hline & $\mathrm{k}^{\prime}$ & - & - & - & - & - & - & - & - & - & - & - & - & - & - & - & - & - & - & - & - \\
\hline \multirow{4}{*}{ Fric. } & $\mathrm{f}$ & - & - & - & - & - & - & - & - & - & - & - & - & - & $\mathrm{x}$ & - & - & - & - & - & - \\
\hline & $\mathrm{s}$ & - & - & $\mathrm{x}$ & $\mathrm{x}$ & - & - & - & - & - & - & - & - & - & - & $\mathrm{x}$ & - & - & - & - & - \\
\hline & $\int$ & - & - & - & - & - & - & - & - & - & - & - & - & - & - & - & - & - & - & - & - \\
\hline & $\mathrm{h}$ & - & - & - & - & - & - & - & - & - & - & - & - & - & - & - & - & $\mathrm{x}$ & - & - & - \\
\hline Aff. & $\mathrm{t} \int$ & - & - & - & - & - & - & - & - & - & - & - & - & - & - & - & - & - & - & - & - \\
\hline \multirow{2}{*}{ Nasals } & $\mathrm{m}$ & $\mathrm{x}$ & - & - & - & $\mathrm{x}$ & - & - & - & $\mathrm{x}$ & - & - & $\mathrm{x}$ & $\mathrm{x}$ & $\mathrm{x}$ & - & - & - & - & - & - \\
\hline & $\mathrm{n}$ & - & $\mathrm{x}$ & $\mathrm{x}$ & - & - & $\mathrm{x}$ & - & - & - & - & $\mathrm{x}$ & $\mathrm{x}$ & - & - & - & - & - & - & - & - \\
\hline \multirow{2}{*}{ Liquids } & 1 & $\mathrm{x}$ & $\mathrm{x}$ & $\mathrm{x}$ & - & - & - & - & - & $\mathrm{x}$ & - & $\mathrm{x}$ & $\mathrm{x}$ & $\mathrm{x}$ & $\mathrm{x}$ & $\mathrm{x}$ & - & - & - & - & - \\
\hline & $\mathrm{r}$ & - & $\mathrm{x}$ & $\mathrm{x}$ & & - & - & - & - & $\mathrm{x}$ & $\mathrm{x}$ & $\mathrm{x}$ & - & $\mathrm{x}$ & $\mathrm{x}$ & $\mathrm{x}$ & - & - & - & - & - \\
\hline \multirow{2}{*}{ Glides } & $\mathrm{w}$ & - & - & - & - & $\mathrm{x}$ & - & - & - & - & - & - & $\mathrm{x}$ & - & - & - & - & - & - & - & - \\
\hline & $\mathrm{j}$ & $\mathrm{x}$ & $\mathrm{x}$ & - & - & - & $\mathrm{x}$ & - & - & $\mathrm{x}$ & - & - & - & - & $\mathrm{x}$ & & $\mathrm{x}$ & $\mathrm{x}$ & $\mathrm{x}$ & - & - \\
\hline
\end{tabular}

Compared to the other classes in Mosittacha, liquids allow more consonants as the second member. Liquids can be followed by stops, ejectives, fricatives, the affricate and nasals. The lateral / $/ /$ allows $/ \mathrm{p} /, / \mathrm{t} /, / \mathrm{k} /, / \mathrm{k} /, / \mathrm{s} /, / \mathrm{J} /, / \mathrm{h} /, / \mathrm{t} \mathrm{f} /$, and $/ \mathrm{m} /$ as the second member in a cluster. By the same token, the flap $/ \mathrm{r} /$ allows $/ \mathrm{t} /, / \mathrm{k} /, / \mathrm{k} /, / \mathrm{f} /, / \mathrm{s} /, / \mathrm{h} /, / \mathrm{t} /$ and $/ \mathrm{m} /$ as the second member in a sequence.

Glides can be followed by stops, implosives, ejectives, fricatives, the affricate, nasals and liquids. The bilabial glide $/ \mathrm{w} /$ can be followed by $/ \mathrm{d} /$ and $/ \mathrm{S} /$. On the other hand, the palatal glide $/ \mathrm{j} /$ can be followed by $/ \mathrm{p} /, / \mathrm{t} /, / \mathrm{d} /, / \mathrm{k} /, / \mathrm{t} \mathrm{f} /, \mathrm{h} /, / 1 /$ and $/ \mathrm{r} /$ as the second member in a non-geminate cluster.

\subsection{Comparison}

It is apparent from the foregoing that consonant sequences in Konso, Diraytata and 
Mosittacha are made up of two non-geminate consonants. Consonant sequences occur only word-medially in both Konso and Mosittacha. However, they occur both word-medially and word-finally in Diraytata. Hence, consonant sequences in Konso and Mosittacha can be analyzed as the coda of the preceding syllable and the onset of the following syllable whereas in Diraytata consonant cluster can be analyzed as either the coda of the preceding syllable and the onset of the following syllable or the coda of the final syllable.

From a close inspection of the phonotactic grid tables in (1-3), one can learn that Konso seems quite different from both Diraytata and Mosittacha in the selection and patterns of non-geminate consonant sequences. The difference between Konso on the one hand and Diraytata and Mosittacha on the other hand lies in the fact that (a) in Konso, stops can occur as the first member of a cluster, whereas such a cluster does not occur in either Diraytata or Mosittacha. (b) In Konso, a cluster of two non-geminate stops occur but this does not happen in either Diraytata or Mosittacha. (c) In Konso, fricatives can be followed by nasals but such a cluster of consonants is impossible in either Diraytata or Mosittacha.

From this state of affairs, the following questions can be raised. (a) Why can stops occur as the first member of a cluster in Konso but not in Diraytata and Mosittacha? (b) Why can two non-geminate stops occur in a cluster in Konso? (c) Why can fricatives occur in Konso preceding a nasal? Now we shall address these questions. These questions will instigate us to consider the history of Konsoid. Black (1974) in his article "Regular metathesis in Gidole" has clearly shown the unique occurrence of metathesis that has taken place in Diraytata in several consonant clusters that are found in Konso:

$$
\begin{array}{ll}
\text { (21) a. sipla } & \text { 'metal' (Konso) } \\
\text { b. silp } & \text { 'metal' (Diraytata) }
\end{array}
$$

Mous (2012:356) has also clearly shown that Mosittacha and Diraytata metathesize several Konso non-geminate clusters. He further remarked that Konso allows liquids and nasals to follow stops, but this is not allowed in Diraytata and Mosittacha because of metathesis. The following examples are taken from Mous (2012:357):

$$
\begin{array}{ll}
\text { (22) a. takmá } & \text { 'honey' (Konso) } \\
\text { b. tayk } & \text { 'honey' (Diraytata) } \\
\text { c. tayka } & \text { 'honey' (Mosittacha) }
\end{array}
$$

As we can see from the examples in (22), in (22a), in Konso, the first member of the cluster is a voiceless velar stop $/ \mathrm{k} /$ and the second member is a bilabial nasal $/ \mathrm{m} /$. In (22b), in Diraytata, the first member becomes the velar nasal $/ \mathrm{y} /$ and the second member becomes the voiceless velar stop / $\mathrm{k} /$. Similarly, in (22c), in Mosittacha, the velar nasal / $\mathrm{y} /$ occurs as a first member of the cluster and the voiceless velar stop $/ \mathrm{k} /$ as a second member. When we compare Konso with Diraytata and Mosittacha, we can learn that in Konso, stops come first followed by nasals, but in both Diraytata and Mosittacha, nasals come first followed by 


\section{The Comparative Phonology of Konsoid}

stops, not the other way around. Moreover, sequences of two non-identical stops are possible in Konso, but such sequences are impossible in both Diraytata and Mosittacha. This situation can take us to the consideration of the Sonority Hierarchy. This is because we believe that phonotactic constraints are guided by a sonority sequencing principle. Thus, consideration of the sonority hierarchy will give us some clues about why, in Konso, stops comes first in a cluster-preceding nasal and why such sequences of clusters are impossible in Diraytata and Mosittacha, and, why clusters of two non-geminate stops are possible in Konso and why such clusters are not possible in either Diraytata or Mosittacha. Now let us see whether or not the sonority hierarchy can give us a solution to the above issues. For the sake of convenience, the sonority hierarchy of Clements (1990) is given in (23):

(23) Sonority Hierarchy

vowels $>$ glides $>$ liquids $>$ nasals $>$ obstruents

According to the Sonority Hierarchy above, sonority decreases as one goes from the left to right. This means that in this hierarchy vowels are the most sonorous and obstruents are least sonorous. Thus, in a non-geminate sequence of consonants, the more sonorous consonant comes preceding the less sonorous consonant. With this idea in mind, now let us consider the case in Konso. That is, in Konso, as we have seen earlier, nasals occur following a stop in a cluster. From the hierarchy in (23), we can learn that nasals come before stops but not stops come preceding a nasal. This is a clear violation of sonority. This is because in the sonority hierarchy given above stops should follow nasals as nasals are more sonorous than stops (obstruents), hence the more sonorous segment should come first in a sequence. As a result, Konso violates this sequential principle. Moreover, non-geminate consonants in a sequence cannot be of the same sonority, but in Konso, in example (2a-c), we have seen that two non-identical stops occur in a cluster. This also violates sonority in that in sonority, it is not allowed to have a cluster of two non-geminate stops. We, therefore, conclude that in Konso, the existence of a cluster of nasals following a stop and also the occurrence of a cluster of two non-identical stops can be accounted for violation of sonority. However, in Konso, the sonority sequencing is conformed in a nasal followed by a stop or a fricative, in a liquid followed by a stop, a fricative or a nasal, and in an approximant followed by a stop, a nasal or a liquid.

Coming to Diraytata and Mosittacha, in both cases, the sonority sequencing is confirmed and there is no violation of sonority. The main reason for keeping the sonority is the metathesis which happens in these languages. The metathesis helps them to resolve the sonority sequencing violation. This is because, for example, takma 'honey' in Konso, the voiceless velar stop $/ \mathrm{k} /$ occurs preceding the bilabial nasal $/ \mathrm{m} /$. This is a clear violation of sonority in that a voiceless stop $/ \mathrm{k} /$, which is less sonorant, occurs preceding the bilabial nasal $/ \mathrm{m} /$, which is more sonorant than a stop. Hence, this in turn violates the sonority 
hierarchy. However, in both Diraytata and Mosittacha, takma 'honey' of Konso becomes tayk 'honey' in Diraytata and tayka 'honey' in Mosittacha. That is to say, the $k t$ sequence of Konso is changed into $\eta k$ of Diraytata and Mosittacha. As a result of metathesis, the sequence of a stop followed by a nasal in Konso is shifted to a nasal followed by a stop in Diraytata and Mosittacha, which resolves the sonority violation.

\section{Syllable structure}

\subsection{The syllable structure in Konso}

Regarding the syllable structure of Konso, Ongaye (2013) has stated that Konso has both open and closed syllables. It does not allow onset or coda clusters. That is to say, both the onset and the coda positions are occupied by a single consonant. As a result, geminate consonants appear as the coda of a preceding syllable and the onset of a following syllable. However, it has a branching nucleus. He further formulates the following four possible syllable structures.

\begin{tabular}{|c|c|c|c|}
\hline (24) & $\mathrm{CV}^{\oplus}$ & po-ra & 'road' \\
\hline & $\mathrm{CVC}$ & dih-ta & 'firefly' \\
\hline & CVV & mii-ra & 'anger' \\
\hline & CVVC & moon-ta & 'sky' \\
\hline
\end{tabular}

\subsection{The syllable structure of Diraytata}

Diraytata has both open and closed syllables. Diraytata does not allow onset clusters but it does allow both nucleus and coda cluster. In other words, it allows a branching nucleus and a coda. As a result, geminate consonants can appear either as the coda of the preceding syllable and the onset of the following syllable or entirely as the coda of the final syllable. According to Wondwosen (2006), it has the following six syllable types:

$\begin{array}{rlll}\text { (25) a. } & \mathrm{CV} & \text { so-ha } & \text { 'meat' } \\ \text { b. } & \mathrm{CVV} & \text { dii-da } & \text { 'males' } \\ \text { c. } & \mathrm{CVVC} & \text { laap-pa } & \text { 'ears' } \\ \text { d. } & \mathrm{CVC} & \text { tor } & \text { 'spear' } \\ \text { e. } & \mathrm{CVC}_{1} \mathrm{C}_{1} & \text { huss } & \text { 'soil' } \\ \text { f. } & \mathrm{CVC}_{1} \mathrm{C}_{2} & \text { fart } & \text { 'horse' }\end{array}$

\subsection{The syllable structure of Mosittacha}

Mosittacha has both open and closed types of syllables. That is to say, a syllable in Mosittacha can end in consonants but no word ends in consonant. It allows a branching nucleus, but it does not allow a branching onset or a coda. Thus, clusters of consonants appear as the onset of the first syllable and the coda of the second syllable. According to

\footnotetext{
(1) The syllable structures in example 21 are taken from Ongaye (2013) with some modifications.
} 


\section{The Comparative Phonology of Konsoid}

Wondwosen (2015), Mosittacha has the following four types of syllables.

$\begin{array}{rlll}\text { (26) a. } & \text { CV } & \text { pa-ra } & \text { 'year' } \\ \text { b. } & \text { CVC } & \text { har-ka } & \text { 'hand' } \\ \text { c. } & \text { CVV } & \text { maa-ka } & \text { 'snake' } \\ \text { d. } & \text { CVVC } & \text { daan-t } f a & \text { 'calabash' }\end{array}$

\subsection{Comparisons}

When we compare the examples in (24-26), we can observe that, a syllable in Konso, Diraytata and Mosittacha consists of an obligatory onset, an obligatory nucleus and an optional coda. In all syllables, onset and nucleus are obligatory. Moreover, they do not allow a branching onset. That is to say, the onset cannot be occupied by more than one consonant. The nucleus position may contain either long or short vowels. Both Konso and Mosittacha have a branching nucleus but not a branching coda. Unlike Konso and Mosittacha, Diraytata has both a branching nucleus and a branching coda. As in $(24,26)$, the four possible syllable structures found in both Konso and Mosittacha are CV, CVC, CVV and CVVC. Regarding Diraytata, as shown in (25) above, there are six possible syllable patterns. When we compare the Diraytata syllable patterns with those of Konso and Mosittacha, we can learn that Diraytata has two more possible syllable types in addition to the Konso and Mosittacha syllable patterns. The two possible syllable types of Diraytata which do not exist in Konso and Mosittacha are $\mathrm{CVC}_{1} \mathrm{C}_{1}$ and $\mathrm{CVC}_{1} \mathrm{C}_{2}$ types. This is because Diraytata allows word-final consonant clusters (or coda cluster), and the cluster could be germination of word-final consonant as in (25e) or cluster of non-geminate consonants as in (25f). The maximum syllable templates for Konso and Mosittacha on the one hand and Diraytata on the other hand are shown in Figure 1-2 below:

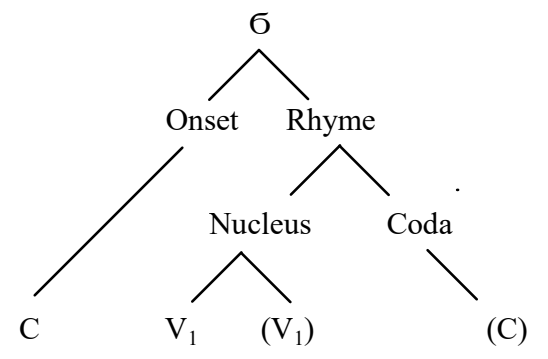

Figure 1. Syllable template of Konso and Mosittacha

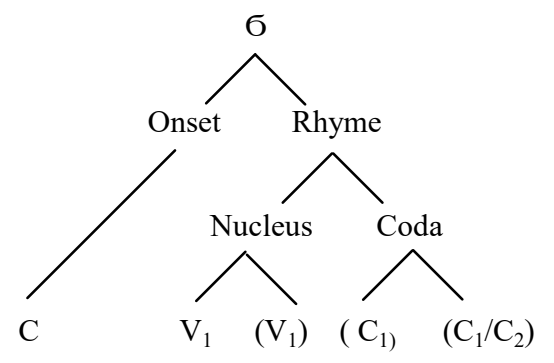

Figure 2. Syllable template of Diraytata

From the figure above, we can learn that in Figure 1, both Konso and Mosittacha allow a non-branching obligatory onset, a branching obligatory nucleus and a non-branching optional coda, whereas in Figure 2, we can see that Diraytata allows a non-branching obligatory onset, a branching obligatory nucleus and a branching optional coda. Therefore, the difference between Konso and Mosittacha on the one hand and Diraytata on the other hand can be accounted for in terms of the presence and absence of an optional branching 
coda.

\section{Conclusion}

So far, we compared the phonological differences and similarities among members of the Konsoid subgroup. Regarding the phonological similarities among the members of the subgroup the following five points have been identified:

(a) All members do not have voiced obstruents.

(b) All members have five short and five long vowels.

(c) Their syllable structures have an obligatory onset, an obligatory nucleus and an optional coda.

(d) All of them do not allow a branching onset.

(e) Their nucleus may contain either short or long vowels.

Regarding the differences between Konso and Mosittacha on the one hand, and Diraytata on the other the following points have been made:

(a) Short vowels with a low tone are devoiced both in Konso and Mosittacha but in Diraytata, short vowels with a low tone are merged with zero, with the exception of the short vowel $/ \mathrm{u} /$.

(b) Geminate consonants in Konso and Mosittacha appear only word-medially but in Diraytata geminate consonants occur both word-medially and word-finally.

(c) The syllable structures of both Konso and Mosittacha allow an obligatory branching nucleus only, whereas the syllable structure of Diraytata allows an obligatory branching nucleus and an optional branching coda.

Regarding the differences between Konso and Diraytata on the one hand, and Mosittacha on the other hand, the following point has been made: the palatal nasal phoneme $/ \mathrm{n} /$ exists both in Konso and Diraytata but it is absent in Mosittacha.

Regarding the differences among Konso, Diraytata and Mosittacha, the following points have come out.

(a) Difference on phonemes

i. In Konso, there are four implosives $/ 6 /, / d /, / f /$ and $/ \mathrm{G} /$, whereas both in Diraytata and Mosittacha there are two implosives $/ 6 /$ and $/ \mathrm{d} /$.

ii. In Konso, there is no ejective consonants at all, but in both Diraytata and Mosittacha there are ejective consonants $/ \mathrm{t} \%, / \mathrm{s} \%, / \mathrm{t} \mathrm{\gamma} /$ and $/ \mathrm{k} \%$

iii. In Konso, there is a voiceless uvular fricative $|\chi|$, but this phoneme is absent in both Diraytata and Mosittacha.

(b) On consonant gemination

Konso allows gemination of all consonants. Diraytata and Mosittacha allow consonant gemination with the exception of the consonants $/ \mathrm{s}^{\prime} /, / \mathrm{t}^{\prime} /, / \mathrm{t} \mathrm{f}^{\prime} /$ and $/ \mathrm{k} \%$. These consonants 


\section{The Comparative Phonology of Konsoid}

do not geminate in both languages.

(c) Constraint on non-geminate consonant cluster

i. Konso allows stops to occur as the first member in a non-geminate cluster but Diraytata and Mosittacha do not allow stops to occur as the first member in a non-geminate cluster.

ii. Konso allows two non-geminate clusters of stops but both Diraytata and Mosittacha do not allow such a cluster.

iii. In Konso fricatives can be followed by nasals in a non-geminate cluster whereas such a cluster is not allowed in either Diraytata or Mosittacha.

The consonant phonemes of the contemporary languages which are developed from the proto-language include retentions and changes. Regarding the retentions, of the eighteen

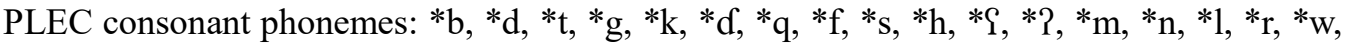
$* \mathrm{j}$, thirteen consonantal phonemes have survived: $\mathrm{t}, \mathrm{k}, \mathrm{R}, \mathrm{d}, \mathrm{f}, \mathrm{s}, \mathrm{h}, \mathrm{m}, \mathrm{n}, \mathrm{l}, \mathrm{r}, \mathrm{w}$ and $\mathrm{j}$. Moreover, the proto- LEC consonant phonemes ${ }^{*} \mathrm{~b},{ }^{*} \mathrm{~d},{ }^{*} \mathrm{~g},{ }^{*} \mathrm{q}$ and ${ }^{*} \mathrm{C}$ have not survived in the Konsoid languages. The major sound changes that have been observed in the Konsoid languages are the merger of voiced stops into their voiceless counterparts and the presence of ejective consonant phonemes which is non-existent in the proto-language. From the foregoing discussion on Konsoid languages we can draw the following concluding remarks: (a) Diraytata is closer to Mosittacha than to Konso because both Diraytata and Mosittacha have developed ejective consonant phonemes. (b) Konso is different from the two languages in that it developed two implosive consonants which do not exist in the other two languages. Therefore, from the discrepancies that exist between Diraytata and Mosittacha on the one hand and Konso on the other hand, in spite of the fact that they have the same kind of genetic and linguistic affiliation, Konso is somewhat different from Diraytata and Mosittacha. This conclusion has been supported by Black (1974:13), who states that "Konsoid is thus perhaps best characterized as a linguistic cline currently well into the process of dividing up into two or more independent languages." Following this I argue that the phonological comparison shows that Konsoid is currently split into two. That is, Konso on the one hand and Diraytata and Mosittacha on the other. However, this conclusion perhaps needs to be further substantiated by lexical, morphological and syntactic contrast.

\begin{tabular}{llll}
\multicolumn{2}{l}{ Abbreviations and Symbols } & & \\
$\sigma$ & Syllable & Impl. & Implosive \\
Aff. & Affricate & Liq. & Liquid \\
C. & Consonant & V. & Vowel \\
Eje. & Ejective & v/s. & Voiceless \\
Fric. & Fricative & &
\end{tabular}




\section{Wondwosen Tesfaye}

\section{References}

Bender, M. L. 1971. The Languages of Ethiopia: A new lexicostatistic classification and some problems of diffusion [J]. Anthropological Linguistics, 13(5):165-288.

Black, P. 1974. Lowland East Cushitic Subgrouping and Reconstruction [D]. Ph.D. Dissertation. New Haven: Yale University.

Bliese, L. 1976. Afar [A]. In M. L. Bender (ed.). The Non-Semitic Languages of Ethiopia [C]. Michigan: Michigan University Press.

Central Statistical Agency. 2008. The 2008 Population and Housing Census for Ethiopia [R]. Results for Southern Nation, Nationalities and People's Region. Vol.11. Addis Ababa.

Clements, G. N.1990. The Role of the Sonority Cycle in Core Syllabification [A]. In J. Kingston \& M. E. Beckman (eds.). Papers in laboratory phonology 1: Between the grammar and physics of speech [C]. Cambridge: Cambridge University Press, 283-333.

Fleming, H. C. 1964. Baiso and Rendille: Somali outliers [J]. Rassegna di Studi Etiopici, 20:35-96.

Harlow, E. 2016. The Phonology of Mosittacha [D]. MA Thesis. Vancouver: Trinity Western University.

Hayward, R. J. 1981. Nominal Suffixes in Dirayta (Gidole) [J]. Bulletin of the School of Oriental and African Studies, 44(1):126-144.

Mous, M. 2012. Cushitic [A]. In Z. Frajzyngier \& E. Shay (eds). The Afro-Asiatic Languages [C]. Cambridge: Cambridge University Press, 342-422.

Ongaye, O. O. 2013. A Grammar of Konso [D]. Ph.D. Dissertation. Leiden: Leiden University.

Sinkeneh, F. 1983. Gidole Phonology [D]. Unpublished Fourth Year Essay. Addis Ababa: Addis Ababa University.

Wondwosen, T. 2006. Aspects of Diraytata Morphology and Syntax: A lexical-functional grammar approach [D]. Ph.D. Dissertation. Trondheim: Norwegian University of Science and Technology.

Wondwosen, T. 2015. A Grammar of Mosittacha [M]. Addis Ababa: Addis Ababa University Press. 